\title{
ARTICLES
}

\section{The Phytoestrogen $\alpha$-Zearalenol Reverses Endothelial Dysfunction Induced by Oophorectomy in Rats}

\author{
Domenica Altavilla, Antonino Saitta, Mariarosaria Galeano, Giovanni Squadrito, \\ Demetrio Marino, Letteria Minutoli, Gioacchino Calapai, Barbara Deodato, \\ Rosario D'Anna, Francesco Corrado, Achille P. Caputi, and Francesco Squadrito
}

Institute of Pharmacology (DA, LM, GC, BD, APC, FS), Department of Internal Medicine (AS, GS), Institute of Plastic Surgery (MG), and Institute of Gynecology (RD, FC), School of Medicine, and Departments of Physiology and Pharmacology (DM), School of Biological Sciences, University of Messina, Messina, Italy

\begin{abstract}
SUMMARY: It has been shown recently that $\alpha$-zearalenol, a resorcyclic acid lactone, prevents bone loss in a rat model of postmenopausal bone loss. We have therefore investigated the effects of this phytoestrogen on endothelial dysfunction induced by estrogen deficiency in rats. Female mature Sprague-Dawley rats underwent a bilateral oophorectomy (OVX rats). Shamoperated animals (sham OVX rats) were used as controls. Three weeks after surgery, animals were randomized to the following treatments: $\alpha$-zearalenol ( $1 \mathrm{mg} / \mathrm{kg} /$ day, im, for 4 weeks), $17 \beta$-estradiol $(20 \mu \mathrm{g} / \mathrm{kg} / \mathrm{day}$, im, for 4 weeks), or their vehicle (100 $\mu \mathrm{l}$, $\mathrm{im}$, of cottonseed oil). Two other groups of rats were treated with $\alpha$-zearalenol or $17 \beta$-estradiol plus the pure estrogen receptor antagonist ICl 182780 (2.5 mg/kg/day, im, for 4 weeks). Mean arterial blood pressure (MAP), heart rate (HR), total plasma cholesterol, plasma estradiol, and plasma $\alpha$-zearalenol were studied. We also investigated endothelial-dependent (acetylcholine, $10 \mathrm{nM}$ to $10 \mu \mathrm{M}$ ) and endothelial-independent (sodium nitroprusside, $15 \mathrm{~nm}$ to $30 \mathrm{~nm}$ ) relaxation of aortic rings, as well as $\mathrm{N}(\mathrm{G})$-methyl-L-arginine (L-NMA: 10 to $100 \mu \mathrm{M}$ )-induced vasoconstriction and calcium-dependent nitric oxide synthase (cNOS) activity in homogenates of lungs taken from both sham OVX rats and OVX rats. Untreated OVX rats had, compared with sham OVX animals, unchanged body weight, MAP, HR, and plasma cholesterol. In contrast oophorectomy reduced plasma estradiol levels (OVX, $2 \pm 0.5 \mathrm{pg} / \mathrm{ml}$; sham OVX, $35 \pm 6 \mathrm{pg} / \mathrm{ml}$ ), impaired endothelial-dependent relaxation and blunted L-NMA-induced contraction (L-NMA $100 \mu \mathrm{M}$ : sham OVX, $2.7 \pm 0.3 \mathrm{~g} / \mathrm{mg}$ tissue; OVX, $1.3 \pm 0.1 \mathrm{~g} / \mathrm{mg}$ tissue). Moreover OVX rats showed a reduced calcium-dependent NO synthase (cNOS) activity. Treatment with $\alpha$-zearalenol or with $17 \beta$-estradiol reverted the endothelial dysfunction and increased cNOS activity in lung homogenates. These effects were abolished by the pure estrogen receptor antagonist $\mathrm{ICI}$ 182780. Our data suggest that $\alpha$-zearalenol improves endothelial-dependent relaxation in OVX rats through an estrogen receptor-mediated effect. (Lab Invest 2001, 81:125-132).
\end{abstract}

$A$ large body of evidence suggests that estrogens play a protective role in the cardiovascular system (Barrett-Connor and Bush, 1991). Observational studies have reported that postmenopausal estrogen therapy protects against cardiovascular disorders (Grady et al, 1992), although a randomized, blinded, placebocontrolled clinical trial for secondary prevention of coronary heart disease in postmenopausal women failed to confirm this evidence (Hulley et al, 1998). The mechanisms by which this protection is mediated remain largely unresolved because the beneficial effects of estrogen on the blood lipid profile only account for $20 \%$ to $30 \%$ of the overall protection (Lip et al, 1997). Growing evidence suggests that estrogens

Received June 30, 2000.

Address reprint requests to: Dr. Domenica Altavilla, Institute of Pharmacology, School of Medicine, University of Messina, Via C. Valeria, Policlinico Gazzi Torre Biologica 5 Piano, 98125 Messina, Italy. E-mail: daltavilla@unime.it have direct effects on the blood vessel wall (Oparil and Arthur, 1999; Seeger et al, 1999; Walsh et al, 1999) and, interestingly, it has been reported that vascular endothelium may play a key role in mediating these effects by producing several vasoactive factors and, more specifically, nitric oxide (NO) (Kleinert et al, 1998). Basal release of NO is higher in females than in males, and oophorectomy diminishes both circulating-estradiol concentration and basal release of $\mathrm{NO}$ to levels seen in males (Hayashi et al, 1992), thus offering an explanation for the protective effect of estradiol against the development of atherosclerosis. In agreement with experimental evidence, estrogen replacement therapy in postmenopausal women improves the impaired endothelial-dependent relaxation (Gerhard et al, 1998), but this evidence has been recently questioned (Van Baal et al, 1999). However, estrogens also have adverse effects on the reproductive system of females (Grady et al, 1995) and males (Robinson et al, 1963) that limits their therapeutic use. 
Therefore it is reasonable to explore the potential of other therapeutic strategies.

Phytoestrogens are nonsteroid compounds present in a variety of dietary products (Wang and Murphy, 1994; Whitten and Naftolin, 1992). The importance of phytoestrogens was first recognized by their effects on sheep fertility, but more recently epidemiologic studies have demonstrated that ingestion of food rich in phytoestrogens may provide protection against certain estrogen-dependent cancers, such as breast and prostate cancers (Barnes et al, 1995; Knight and Eden, 1995, 1996). Phytoestrogens also have antioxidant, radical scavenging, hypolipidemic, and serum cholesterol-lowering properties (Franke et al, 1994). Several categories of phytoestrogens have been identified, including lignans, isoflavonoids, coumestans, and resorcyclic acid lactones. All of these compounds bind to estrogen receptors.

Zearalenone, a resorcyclic acid lactone, has been used previously in the food industry to promote growth in beef cattle. Zearalenone is metabolized in the presence of NADPH and UDPglucuronosyltransferase into $\alpha$-zearalenol and $\beta$-zearalenol (Jimenez and Mateo, 1997). Because $\alpha$-zearalenol showed a greater ability to bind to estrogen receptors than both zearalenone and $\beta$-zearalenol (Fitzpatrick et al, 1989), the $\alpha$-isomer has been tested successfully in a model of postmenopausal bone loss (Draper et al, 1997). In this model the phytoestrogen was able to reduce bone loss and resorption, likely by acting as an estrogen agonist. However no data are available about the effects of $\alpha$-zearalenol on the cardiovascular apparatus, especially in the presence of estrogen deficiency.

Using an experimental model of endothelial dysfunction induced by oophorectomy in female rats that resembles the impairment in endothelium-dependent vasodilatation observed in postmenopausal women, we investigated whether $\alpha$-zearalenol and $17 \beta$ estradiol exert the same degree of protection against the decline of vascular function in OVX rats.

\section{Results}

\section{Mean Arterial Blood Pressure, Heart Rate, Body Weight, and Uterine Assay}

Bilateral oophorectomy did not modify mean arterial blood pressure (MAP), heart rate (HR), and body weight. Supplementation with both $17 \beta$-estradiol and $\alpha$-zearalenol did not cause any significant change of these parameters in sham oophorectomized (sham OVX) and oophorectomized (OVX) rats throughout the study. MP and $\mathrm{HR}$ ranged from $101 \pm 12 \mathrm{mmHg}$ to $108 \pm 13 \mathrm{mmHg}$ and from $339 \pm 15$ beats/minute to $366 \pm 13$ beats/minute, respectively. Changes in body weight were similar among groups and ranged from $245 \pm 13 \mathrm{~g}$ to $290 \pm 14 \mathrm{~g}$.

Uterine weights were decreased by more than $30 \%$ to $35 \%$ in the OVX control (vehicle) group compared with sham OVX rats, and $\alpha$-zearalenol-supplemented OVX rats showed a similar decline (Fig. 1). The OVX rats treated with $17 \beta$-estradiol had a significantly
Uterine weights

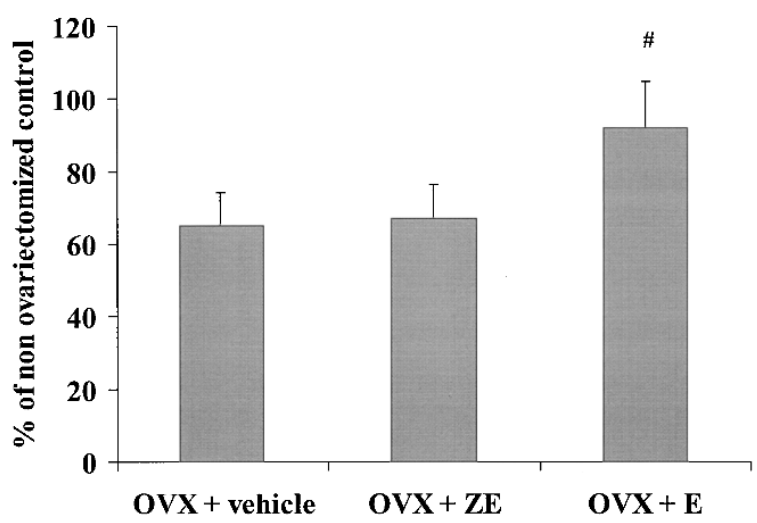

Figure 1.

Uterine weights in oophorectomized (OVX) rats treated daily with vehicle (100 $\mu \mathrm{l}$, im, of cottonseed oil), $\alpha$-Zearalenol (ZE; $1 \mathrm{mg} / \mathrm{kg}$, im, in $100 \mu \mathrm{l}$ of cottonseed oil), or $17 \beta$-estradiol (E; $20 \mu \mathrm{g} / \mathrm{kg}$, im, in $100 \mu \mathrm{l}$ cottonseed oil). Mean weights were determined for each treatment group and compared with untreated sham OVX rats. Each point represents the mean \pm SEM of seven experiments. $\# p<0.01$ versus vehicle.

higher mean uterine weight than either vehicle- or $\alpha$-zearalenol-treated rats (Fig. 1).

\section{Plasma 17 $\beta$-Estradiol, $\alpha$-Zearalenol, and Total Cholesterol Levels}

Plasma $17 \beta$-estradiol levels were significantly reduced in OVX rats compared with sham OVX rats (Table 1). Estrogen replacement therapy markedly increased plasma $17 \beta$-estradiol to levels resembling those observed in sham OVX rats (Table 1). In contrast, $\alpha$-zearalenol supplementation did not cause any change of $17 \beta$-estradiol levels (Table 1 ) in either OVX rats or sham OVX rats.

Plasma $\alpha$-zearalenol levels were less than $1 \mathrm{ng} / \mathrm{ml}$ in OVX and sham OVX rats treated with both vehicle and $17 \beta$-estradiol. Supplementation with $\alpha$-zearalenol markedly increased the plasma levels of this phytoestrogen in both OVX and sham OVX rats.

Plasma total cholesterol levels were not significantly changed in OVX rats compared with sham OVX rats. Furthermore neither estrogen replacement therapy nor $\alpha$-zearalenol supplementation produced any change of this lipid parameter in both OVX rats and sham OVX rats (Table 1).

\section{Vessel Reactivity}

Endothelium-dependent relaxation (acetylcholine [Ach], $10 \mathrm{~nm}$ to $10 \mu \mathrm{m}$ ) and endothelium-independent relaxation (sodium nitroprusside [SN], $15 \mathrm{~nm}$ to $30 \mathrm{~nm}$ ) of thoracic aortas precontracted with phenylephrine (PE; $100 \mathrm{~nm}$ ) were studied at the end of treatment. Oophorectomy markedly reduced the relaxant effect of ACh (Fig. 2), but did not produce any significant change in the relaxant effect caused by SN (Fig. 3). Estrogen replacement therapy or $\alpha$-zearalenol supplementation did not modify the relaxant effects of ACh and $\mathrm{SN}$ in sham OVX rats (Figs. 2 and 3). In contrast 
Table 1. Plasma $17 \beta$ Estradiol, $\alpha$-Zearalenol, and Cholesterol Levels in Oophorectomized (OVX) or Sham Oophorectomized (Sham OVX) Rats Treated with $\alpha$-Zearalenol (ZE), 17 $\beta$ Estradiol (E), ZE Plus ICI 182780, E Plus ICI 182780, and Their Vehicle

\begin{tabular}{lccc}
\hline \multicolumn{1}{c}{ Group } & $\begin{array}{c}17 \beta \text { estradiol } \\
(\mathrm{pg} / \mathrm{ml})\end{array}$ & $\begin{array}{c}\alpha \text {-zearalenol } \\
(\mathrm{ng} / \mathrm{ml})\end{array}$ & $\begin{array}{c}\text { Cholesterol } \\
(\mathrm{mmol} / \mathrm{l})\end{array}$ \\
\hline Controls & $34 \pm 6$ & $<1$ & $2.2 \pm 0.2$ \\
Sham OVX + vehicle & $35 \pm 6$ & $<1$ & $3.3 \pm 0.7$ \\
Sham OVX + ZE & $30 \pm 7$ & $4.3 \pm 2.1$ & $3.4 \pm 0.5$ \\
Sham OVX + E & $55 \pm 5$ & $<1$ & $2.5 \pm 0.8$ \\
OVX + vehicle & $2 \pm 0.5^{*}$ & $<1$ & $3.5 \pm 0.4$ \\
OVX + ZE & $3 \pm 2.1^{*}$ & $<.1 \pm 1.8^{* *}$ & $2.7 \pm 0.5$ \\
OVX + E & $27 \pm 6^{* *}$ & $4.7 \pm 1.9^{* *}$ & $2.5 \pm 0.6$ \\
OVX + ZE + ICI 182780 & $4 \pm 2.9$ & $<1$ & $2.8 \pm 1.2$ \\
OVX + E + ICl 182780 & $29 \pm 67^{* *}$ & $3.3 \pm 0.9$ \\
\hline
\end{tabular}

Each point represents the mean \pm SEM of six experiments.

${ }^{\star} p<0.001$ vs sham OVX; ${ }^{* *} p<0.001$ vs OVX + vehicle.

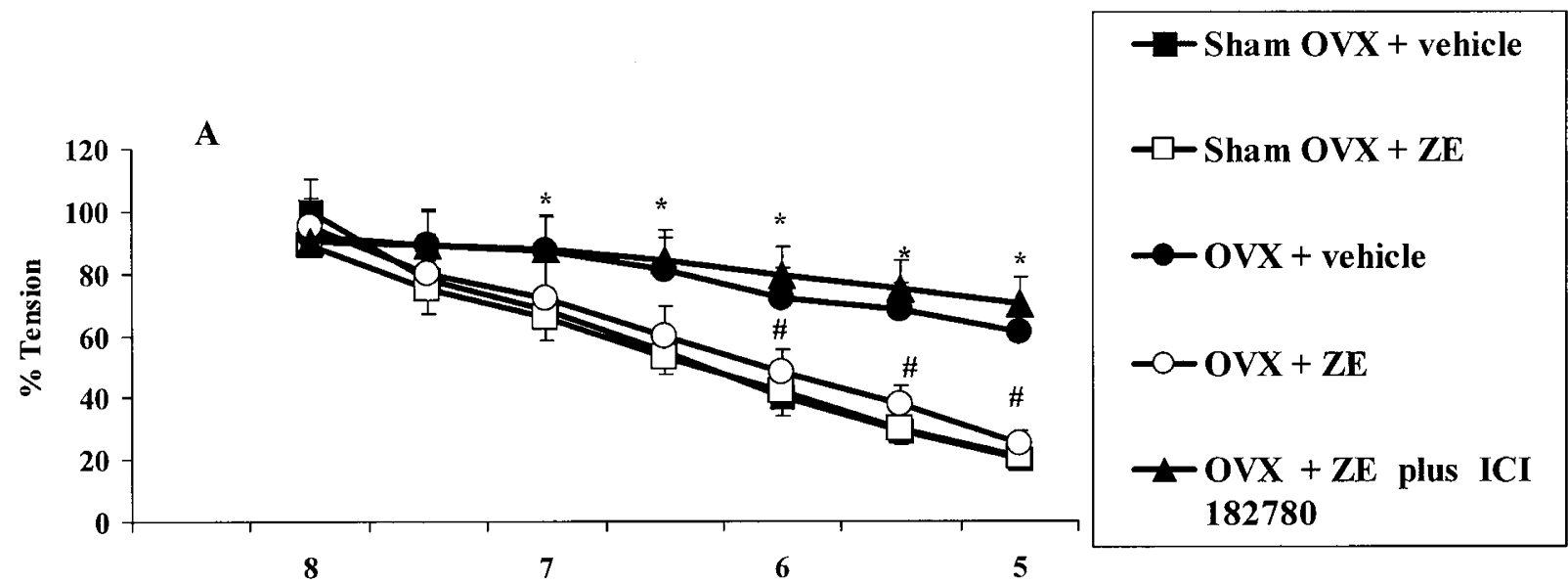

Acetylcholine $[-\log \mathrm{M}]$
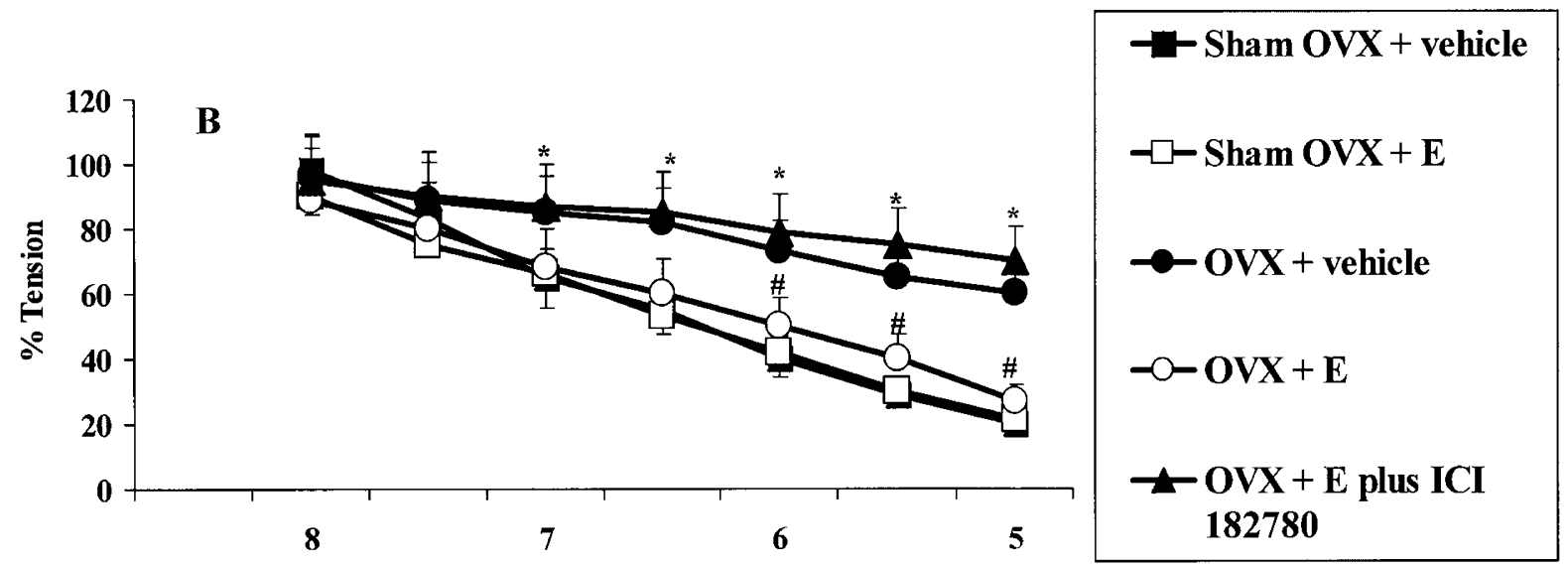

Acetylcholine $[-\log \mathrm{M}]$

Figure 2.

A, Relaxant effect of acetylcholine (ACh) in aortic rings (contracted with phenylephrine [PE], $100 \mathrm{~nm}$ ) from sham OVX and OVX rats treated daily with $\alpha$-Zearalenol (ZE; $1 \mathrm{mg} / \mathrm{kg}$, im, in $100 \mu \mathrm{l}$ of cottonseed oil), ZE plus ICI 182780 (2.5 mg/kg, im, in $100 \mu$ l of cottonseed oil), or vehicle (100 $\mu$, im, of cottonseed oil). Each point represents the mean \pm SEM of six experiments. ${ }^{*} p<0.001$ versus sham $\mathrm{OVX}$ and $\mathrm{OVX}+\mathrm{ZE} ; \# p<0.005$ versus $\mathrm{OVX}+$ vehicle. B, Relaxant effect of $\mathrm{ACh}$ in aortic rings (contracted with PE $100 \mathrm{~nm}$ ) from sham OVX and OVX rats treated daily with $17 \beta$-estradiol (E; $20 \mu \mathrm{g} / \mathrm{kg}$, im, in $100 \mu \mathrm{l}$ cottonseed oil), E plus ICl 182780 (2.5 $\mathrm{mg} / \mathrm{kg}$, im, in $100 \mu \mathrm{l}$ of cottonseed oil), or vehicle (100 $\mu \mathrm{l}$, im, of cottonseed oil). Each point represents the mean \pm SEM of six experiments. * $p<0.001$ versus sham OVX and OVX + ZE; \# $p<0.005$ versus $\mathrm{OVX}+$ vehicle. 

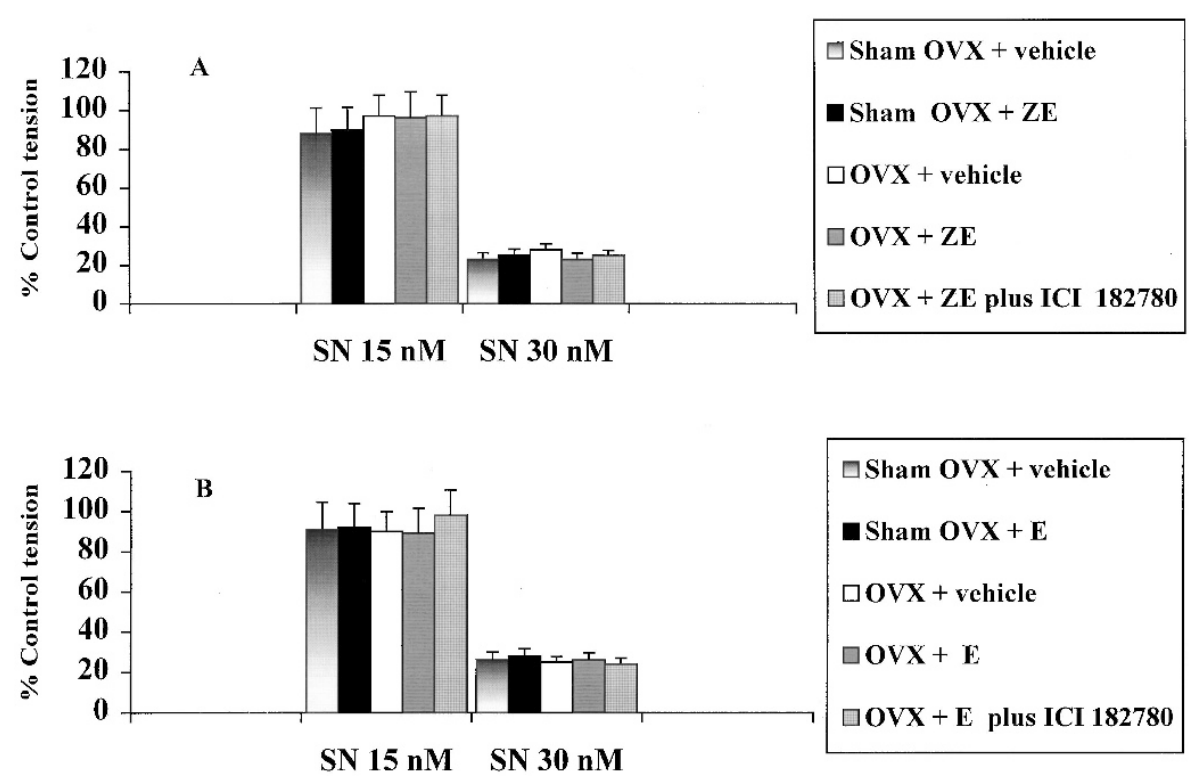

\section{Figure 3.}

A, Relaxant effect of sodium nitroprusside (SN; 15 and $30 \mathrm{~nm}$ ) in aortic rings (contracted with PE, $100 \mathrm{~nm}$ ) from sham OVX and OVX rats treated daily with $\alpha$-Zearalenol (ZE; $1 \mathrm{mg} / \mathrm{kg}$, im, in $100 \mu \mathrm{l}$ of cottonseed oil), ZE plus ICI 182780 (2.5 mg/kg, im, in $100 \mu$ l of cottonseed oil), or vehicle (100 $\mu$ l, im, of cottonseed oil). Each point represents the mean \pm SEM of six experiments. B, Relaxant effect of SN (15 and $30 \mathrm{~nm}$ ) in aortic rings (contracted with PE, $100 \mathrm{~nm}$ ) from sham OVX and OVX rats treated daily with $17 \beta$-estradiol (E; $20 \mu \mathrm{g} / \mathrm{kg}$, im, in $100 \mu \mathrm{l}$ cottonseed oil), E plus ICl 182780 (2.5 mg/kg, im, in $100 \mu \mathrm{l}$ of cottonseed oil), and vehicle (100 $\mu \mathrm{l}$, im, of cottonseed oil). Each point represents the mean \pm SEM of six experiments.

both treatments succeeded in improving the impairment in endothelium-dependent relaxation of OVX rats and no significant difference was observed between these two active treatments (Fig. 2). Furthermore, ICI
182780, a pure estrogen receptor antagonist, abolished the beneficial effect of both $17 \beta$-estradiol and $\alpha$-zearalenol on endothelial-dependent relaxation (Fig. 2).
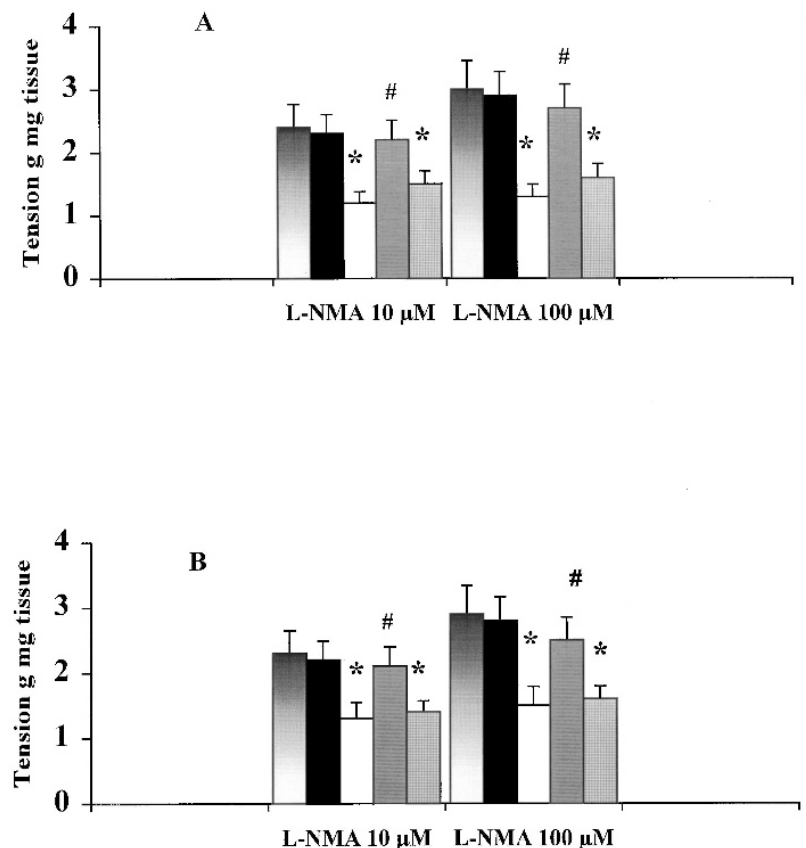

\begin{tabular}{|l|}
\hline Sham OVX + vehicle \\
Sham OVX + ZE \\
$\square$ OVX + vehicle \\
$\square$ OVX + ZE \\
$\square O V X+$ ZE plus ICI 182780
\end{tabular}

$\square$ Sham OVX + vehicle

שSham OVX + E

$\square O V X+$ vehicle

$\square \mathbf{O V X}+\mathbf{E}$

$\square O V X+E$ plus ICI 182780

Figure 4.

A, Effects of N(G)-methyl-L-arginine (L-NMA; 10 and $100 \mu \mathrm{M}$ ) on maximal contractile response to PE in aortic rings taken from sham OVX and OVX rats treated daily with $\alpha$-Zearalenol (ZE; $1 \mathrm{mg} / \mathrm{kg}$, im, in $100 \mu$ l of cottonseed oil), ZE plus ICl 182780 (2.5 mg/kg, im, in $100 \mu \mathrm{l} \mathrm{of} \mathrm{cottonseed} \mathrm{oil),} \mathrm{or} \mathrm{vehicle} \mathrm{(100} \mu$ l, im, of cottonseed oil). Each point represents the mean \pm SEM of six experiments. $\# p<0.001$ versus $O V X+$ vehicle; ${ }^{*} p<0.005$ versus sham $0 V X$ and $O V X+Z E$. B, Effects of L-NMA $(10$ and $100 \mu \mathrm{M})$ on maximal contractile response to PE in aortic rings taken from sham OVX and OVX rats treated daily with $17 \beta$-estradiol $(\mathrm{E} ; 20 \mu \mathrm{g} / \mathrm{kg}$, im, in 100 $\mu \mathrm{l}$ cottonseed oil), E plus ICl 182780 (2.5 mg/kg, im, in $100 \mu \mathrm{l}$ of cottonseed oil), and vehicle (100 $\mu \mathrm{l}$, im, of cottonseed oil). Each point represents the mean \pm

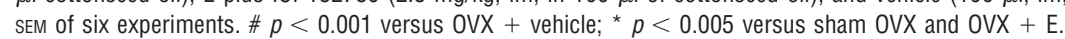


Addition of $\mathrm{N}(\mathrm{G})$-methyl-L-arginine (L-NMA; 10 to $100 \mu \mathrm{M})$ to the organ bath caused a significant contraction of the aortic rings precontracted with PE (Fig. 4). L-NMA-induced vasoconstriction was significantly blunted in OVX rats compared with sham OVX rats. Estrogen replacement therapy or $\alpha$-zearalenol supplementation markedly increased the constrictor response elicited by L-NMA and no significant difference was observed between these two regimens (Fig. 4). The pure estrogen receptor antagonist ICI 182780 abated these effects (Fig. 4). Finally, neither of the active treatments changed L-NMA-induced responses in sham OVX rats (Fig. 4).

\section{Nitric Oxide Synthase Activity}

$\mathrm{Ca}^{2+}$-dependent NO synthase (cNOS) activity was investigated in lung homogenates at the end of treatment (Table 2). OVX rats showed a marked decrease in NO synthase (NOS) activity compared with sham OVX animals (Table 2). Estrogen replacement therapy or $\alpha$-zearalenol supplementation markedly enhanced the activity of NOS in lung homogenates. This effect was completely reverted by the concomitant treatment with $\mathrm{ICl}$ 182780. Neither estrogen therapy nor $\alpha$-zearalenol treatment modified cNOS activity in sham OVX rats. Furthermore the addition of L-NMA to the incubation buffer effectively inhibited NOS activity in the lung, providing further evidence that NOS was being measured.

\section{Discussion}

Several reports have suggested that some effects of phytoestrogens are mediated through their ability to bind to estrogen receptors (Makela et al, 1995; Miksicek, 1994). This is supported by the observation that certain phytoestrogens, such as genistein, coumestrol, or zearalenol, are able to bind to the estrogen receptors and modulate a variety of estrogendependent processes (Stahl et al, 1998). Furthermore it has been suggested that $\alpha$-zearalenol shows interesting bioactivity in preventing bone loss in a well- recognized model of postmenopausal osteoporosis in the rat (Draper et al, 1997).

With this background, we attempted to determine if the protective effects of $\alpha$-zearalenol supplementation on the cardiovascular apparatus may be mediated, in part, by an increased production of endothelial NO from the vascular endothelium. To test this hypothesis we performed a comparison study on the effects of $\alpha$-zearalenol and $17 \beta$-estradiol in endothelial dysfunction induced by bilateral oophorectomy in female rats.

Our results suggest that OVX rats developed a typical endothelial dysfunction resembling that observed in postmenopausal women. More specifically they had a markedly reduced relaxant response to $\mathrm{ACh}$, an endothelium and $\mathrm{NO}$-dependent relaxant agent, and unchanged response to $\mathrm{SN}$, an endothelium and $\mathrm{NO}$-independent relaxing compound. In addition aortic rings prepared from OVX rats showed a reduced contraction in response to L-NMA, an inhibitor of NO synthase. These data suggest that OVX rats show a marked impairment in the L-arginine/NO pathway characterized by a blunted production of endothelial NO. This blunted endothelial NO release seems to be the consequence of a decreased activity of the enzyme devoted to its regulation, the constitutive NO synthase. Indeed lung homogenates prepared from OVX rats showed a reduced constitutive NO synthase activity compared with sham OVX rats. This disturbance in the L-arginine/NO pathway has already been proposed to explain the endothelial dysfunction observed in postmenopausal women (Gerhard et al, 1998). In contrast the plasma levels of cholesterol were unchanged in OVX rats, which suggests that this present model (4 weeks of estrogen deficiency) causes a selective impairment in the L-arginine/NO pathway (endothelial dysfunction) without other important confounding alterations. The major finding of this study is that $\alpha$-zearalenol supplementation succeeded in reverting the impaired endothelial dysfunction observed in OVX rats. This compound was able to restore the endothelium-dependent relaxation, likely through an increased production of basal endothelial NO release; in fact $\alpha$-zearalenol treatment increased

Table 2. Calcium-Dependent (cNOS) and Calcium-Independent (iNOS) Nitric Oxide Synthase Activity in Lung of OVX or Sham OVX Rats Treated with $\alpha$-Zearalenol (ZE), $17 \beta$ Estradiol (E), ZE Plus ICI 182780, E Plus ICI 182780 and Their Vehicle

\begin{tabular}{lccc}
\hline \multicolumn{1}{c}{ Group } & cNOS & iNOS & Total NOS + L-NMA \\
\hline Controls & $18.5 \pm 3.5$ & $2.5 \pm 0.7$ & $2.3 \pm 1.1$ \\
Sham OVX + vehicle & $19.3 \pm 4.1$ & $2.8 \pm 1.2$ & $2.1 \pm 0.7$ \\
Sham OVX + ZE & $21.2 \pm 3.4$ & $2.8 \pm 1.7$ & $2.3 \pm 1.1$ \\
Sham OVX + E & $23.8 \pm 6.7$ & $2.8 \pm 1.5$ & $1.9 \pm 1.2$ \\
OVX + vehicle & $10.3 \pm 2.8^{*}$ & $2.7 \pm 1.8$ & $1.2 \pm 0.7$ \\
OVX + ZE & $18.1 \pm 3.6^{* *}$ & $2.3 \pm 1.5$ & $2.1 \pm 0.5$ \\
OVX + E & $19.6 \pm 1.9^{* *}$ & $2.2 \pm 1.8$ & $1.7 \pm 0.6$ \\
OVX + ZE + ICl 182780 & $8.9 \pm 2.1^{*}$ & $2.5 \pm 2.2$ & $2.3 \pm 1.8$ \\
OVX + E + ICI 182780 & $9.3 \pm 2.5^{*}$ & $2.4 \pm 1.9$ & $1.8 \pm 0.5$ \\
\hline
\end{tabular}

NOS activity was expressed as pmol citrulline 20 min per mg protein and shown as mean \pm SEM of six experiments.

${ }^{\star} p<0.001$ vs sham OVX; ${ }^{* *} p<0.001$ vs OVX + vehicle. 
the constrictor response elicited by L-NMA. This result strongly supports the idea that the phytoestrogen treatment was able to enhance the depressed Larginine/NO pathway. From a mechanistic point of view it can be proposed that $\alpha$-zearalenol increases the activity of endothelial NOS; indeed lung homogenates prepared from phytoestrogen-supplemented OVX rats showed an increased activity of this enzyme isoform. As far as we know, this paper represents the first report indicating that this naturally occurring phytoestrogen stimulates in vivo the activity of endothelial NOS. It is likely that $\alpha$-zearalenol increases endothelial NOS activity in the rat aorta through a rapid receptormediated $\mathrm{Ca}^{2+}$ translocation of the enzyme without causing any change in endothelial NO synthase gene expression, as has been shown recently for $17 \beta$ estradiol (Barbacanne et al, 1999; Goetz et al, 1999).

The second important finding of this study is that $\alpha$-zearalenol and $17 \beta$-estradiol showed overlapping effects in endothelial dysfunction. In fact, in our experimental model, the well-known ability of estrogen replacement therapy to revert endothelial dysfunction during estrogen deficiency was nicely reproduced by $\alpha$-zearalenol supplementation. No statistical differences were, in fact, observed between these two active treatments. In contrast, although $17 \beta$-estradiol significantly modifies uterine weights, the beneficial effects of $\alpha$-zearalenol on the cardiovascular apparatus was not accompanied by any change in uterus weight.

Estrogen receptors are present in the blood vessel wall (Losordo et al, 1994) and $\alpha$-zearalenol acts as estrogen agonist on these structures (Collins and McLachlan, 1997). To confirm this we carried out experiments with the pure estrogen receptor antagonist ICI 182780 (al-Matubsi et al, 1998). Our results clearly indicate that blocking the estrogen receptor abolished the beneficial effects of $\alpha$-zearalenol on endothelium dysfunction, thus strongly supporting the hypothesis that the $\alpha$-zearalenol serves as an estrogen receptor agonist.

In conclusion, our findings suggest that $\alpha$-zearalenol-induced augmentation of NO production may contribute to its beneficial cardiovascular effects.

\section{Materials and Methods}

\section{Animals}

All procedures performed on animals were approved by the Ethical Committee of the University of Messina and were consistent with the Guide for the Care and Use of Laboratory Animals (NIH Publication No. 8523, revised 1987). OVX female mature Sprague-Dawley rats (Charles River Labs, Calco, Italy) were maintained at constant humidity $(60 \pm 5 \%)$, temperature $(24 \pm$ $\left.1^{\circ} \mathrm{C}\right)$, and light cycle (6 am to $\left.6 \mathrm{pm}\right)$, and were given free access to a semipurified chow with poor phytoestrogen content and to drinking water. Sham OVX rats were used as controls.

\section{Estrogen and $\alpha$-Zearalenol Supplementation}

Three weeks after surgery, OVX rats and sham OVX animals were randomly assigned to one of the five treatment groups. The first group received daily injections of $17 \beta$-estradiol $(20 \mu \mathrm{g} / \mathrm{kg}$, im, in $100 \mu \mathrm{l}$ cottonseed oil, daily), the second group was given $\alpha$-zearalenol ( $1 \mathrm{mg} / \mathrm{kg}$, im, in $100 \mu$ l cottonseed oil, daily), the third group was treated with $17 \beta$-estradiol plus the pure estrogen antagonist ICl 182780 (alMatubsi et al, 1998) $(2.5 \mathrm{mg} / \mathrm{kg}$, im, in $100 \mu \mathrm{l}$ cottonseed oil, daily), the fourth group was treated with $\alpha$-zearalenol plus the pure estrogen antagonist ICI 182780 , and the fifth group received the $17 \beta$-estradiol, $\alpha$-zearalenol, and ICI 182780 vehicle $(100 \mu \mathrm{l}$, im, of cottonseed oil daily). The treatment lasted 4 weeks. The doses of $17 \beta$-estradiol and $\alpha$-zearalenol were selected according to previous studies of the effects of both compounds in OVX rats (Draper et al, 1997; Squadrito et al, 1996). It has been suggested that the estrogenic potency of $\alpha$-zearalenol relative to $17 \beta$ estradiol is 50 times less (Everett et al, 1987).

\section{Mean Arterial Blood Pressure, Heart Rate, Body Weight, and Uterine Assay}

MAP and HR were measured using the tail cuff method at baseline conditions and after 4 weeks of treatment. Body weight (in milligrams) was also monitored at the same time points. At the end of the experiment, the uteri were removed and weighed.

\section{Measurement of Plasma-Estradiol, $\alpha$-Zearalenol, and Total Cholesterol Levels}

Plasma $17 \beta$-estradiol, $\alpha$-zearalenol, and total cholesterol levels were studied when the animals were killed. Plasma $17 \beta$-estradiol levels were determined by radioimmunoassay with a commercially available kit. Assay sensitivity was $1.0 \mathrm{pg} / \mathrm{ml}$, and intra-assay and interassay coefficients of variation for estradiol were $5.3 \%$ and $6.4 \%$, respectively. Plasma $\alpha$-zearalenol levels were assayed using high-performance liquid chromatography with fluorescence detection (Prelusky et al, 1989). Assay sensitivity was $1 \mathrm{ng} / \mathrm{ml}$ and recovery was $85 \%$ to $93 \%$. The cholesterol in the blood was determined by an enzymatic cholesterol esterase/cholesterol oxidase using an automatic analysis technique on a chemical analyzer.

\section{Vessel Reactivity Studies}

At the end of the treatment period, heparinized rats were killed with an overdose of sodium pentobarbital (75 mg/kg, ip). Thoracic aortas were removed and placed in cold Krebs solution of the following composition: $\mathrm{NaCl} 118.4 \mathrm{~nm}, \mathrm{KCl} 4.7 \mathrm{~nm}, \mathrm{MgSO}_{4} 1.2 \mathrm{~nm}$, $\mathrm{CaCl}_{2} 2.5 \mathrm{~nm}, \mathrm{KH}_{2} \mathrm{PO}_{4} 1.2 \mathrm{~nm}, \mathrm{NAHCO}_{3} 25.0 \mathrm{~nm}$, and glucose $11.7 \mathrm{~nm}$. Aortas were then cleaned of adherent connective and fat tissue and cut into rings approximately $2 \mathrm{~mm}$ in length. Rings were then placed under $1 \mathrm{~g}$ of tension in an organ bath containing $10 \mathrm{ml}$ Krebs solution at $37^{\circ} \mathrm{C}$ and bubbled with $95 \% \mathrm{O}_{2}$ and 
$5 \% \mathrm{CO}_{2}(\mathrm{pH} 7.4)$. All experiments were carried out in the presence of indomethacin $(10 \mu \mathrm{M})$ to exclude the involvement of eicosanoids and their metabolites. Developed tension was measured with an isometric force transducer and recorded on a polygraph (Ugo Basile, Varese, Italy). After an equilibration period of 60 minutes during which the rings were washed with fresh Krebs solution at 15- to 20-minute intervals, basal tension was readjusted to $1 \mathrm{~g}$ and the tissue was exposed to PE (100 nM). When the contraction was stable, the functional integrity of the endothelium was assessed by a relaxant response to ACh (100 nm). The tissue was then washed occasionally for 30 minutes.

Endothelium-dependent relaxation was evaluated with cumulative concentrations of ACh $(10 \mathrm{nM}-1 \mu \mathrm{M})$ in aortic rings precontracted with PE (100 nM). Endothelium-independent relaxation was investigated by analyzing the relaxant effects of SN (15-30 nm), as previously described (Squadrito et al, 1997). Relaxation of the rings was calculated as the percentage decrease of contractile force. Some rings were precontracted with PE and then incubated with L-NMA $(10-100 \mu \mathrm{M})$ and the results were expressed as grams of tension per milligram of tissue.

\section{NOS Activity}

To measure NOS activity, the lungs were removed at the end of the experiment, immediately frozen in liquid nitrogen, and later assayed according to the method of Bredt and Snyder (1990) with slight modifications. Briefly, tissues were homogenized on ice in 10 volumes of homogenizing buffer: Tris $\mathrm{HCl} 50 \mathrm{~mm}$, EDTA $0.1 \mathrm{~mm}$, Pefabloc $1 \mathrm{~mm}$, and dithiothreitol $1 \mathrm{~mm}$. A $50-\mu$ l sample of the homogenate was incubated with $50 \mu \mathrm{l}$ of incubation buffer for 20 minutes at $37^{\circ} \mathrm{C}$. The incubation buffer contained the following cofactors: L-arginine $10 \mu \mathrm{M},\left[{ }^{3} \mathrm{H}\right] \mathrm{L}$-arginine 5 pmol, NADPH $1 \mathrm{~mm}$, calmodulin $30 \mathrm{~nm}$, tetrahydrobiopterin $5 \mu \mathrm{M}$, calcium 2 $\mathrm{mm}$, and L-valine $60 \mathrm{~mm}$ in a Tris buffer at $\mathrm{pH}$ 7.4. To determine calcium-independent NOS activity, a buffer replacing the calcium with EGTA (5 mm) was used. Nonspecific conversion of arginine to citrulline was determined in the absence of NADPH and a separate buffer containing L-NMA (1 $\mathrm{mm}$ ) provided further evidence that NOS was being measured.

After the 20-minute incubation, the reaction was stopped by the addition of $1 \mathrm{ml}$ of ice-cold stop buffer (containing HEPES $20 \mathrm{~mm}$, EGTA $2 \mathrm{~mm}$, and EDTA 2 $\mathrm{mm}$ at $\mathrm{pH}$ 5.5). The reaction mixture was applied to 1-ml Dowex columns (NA+ form, $50 \mathrm{~W}$, mesh size 100 to 200) that had previously been equilibrated with $1 \mathrm{ml}$ of stop buffer. The eluate was collected and the columns washed twice with $0.75 \mathrm{ml}$ deionized water to retrieve any residual activity. A $400-\mu l$ sample of the elute was taken for scintillation counting. The protein concentration of the homogenates was determined by the Bradford assay (Bradford, 1976) using BSA (fraction V) as a standard.

\section{Drugs}

$\alpha$-Zearalenol and $17 \beta$-estradiol were obtained from Sigma Chemical Company (St. Louis, Missouri). ICl 182780 was a kind gift of Dr. Salvatore Guarini, University of Modena, Italy.

\section{Statistical Analysis}

Data are expressed as means \pm SEM. Results of the before versus after treatment measurements (MAP, $\mathrm{HR}$, and body weight) were analyzed using the paired $t$ test. For the other data, comparison between the means of the two groups was performed using ANOVA followed by the Bonferroni test, and was considered significant at $p<0.05$.

\section{References}

al-Matubsi HY, Fairclough RJ, and Jenkin G (1998). Oestrogenic effects of $\mathrm{ICl} 182,780$, a putative anti-oestrogen, on the secretion of oxytocin and prostaglandin F2 $\alpha$ during oestrous cycle in the intact ewe. Anim Reprod Sci 51:81-96.

Barbacanne MA, Rami J, Michel JB, Souchard JP, Philippe M, Besombes JP, Bayard F, and Arnal JF (1999). Estradiol increases rat aorta endothelium-derived relaxing factor (EDRF) activity without changes in endothelial NO synthase gene expression: Possible role of decreased endotheliumderived superoxide anion production. Cardiovasc Res 41: 672-681.

Barnes S, Peterson GT, and Coward L (1995). Rationale for the use of genistein-containing soy matrices in the chemoprevention trials for breast and prostate cancer. J Cell Biochem 22:181-187.

Barrett-Connor $\mathrm{H}$ and Bush TL (1991). Estrogen and coronary heart disease in women. JAMA 265:1861-1867.

Bradford MM (1976). A rapid and sensitive method for the quantification of protein dye binding. J Biol Chem 72:700703.

Bredt DS and Snyder SH (1990). Isolation of nitric oxide synthase, a calmodulin-requiring enzyme. Proc Natl Acad Sci USA 87:682-685.

Collins BM, McLachlan JA, Arnold SF (1997). The estrogenic and antiestrogenic activities of phytochemicals with the human estrogen receptor expressed in yeast. Steroids 62 : 365-372.

Draper CR, Edel MJ, Dick IM, Randall AG, Martin GB, and Prince $R L$ (1997). Phytoestrogens reduce bone loss and bone resorption in oophorectomized rats. J Nutr 127:1795-1799.

Everett DJ, Perry CJ, Scott KA, Martin BW, and Terry MK (1987). Estrogenic potencies of resorcyclic acid lactones and $17 \beta$-estradiol in female rats. J Toxicol Environ Health 20:435443.

Fitzpatrick DW, Picken CA, Murphy LC, and Buhr BN (1989). Measurement of the relative binding affinity of zearalenone, $\alpha$-zearalenol and $\beta$-zearalenol for uterine and oviduct estrogen receptors in swine, rats and chickens: An indicator of estrogenic potencies. Comp Biochem Physiol C 94:691-694.

Franke AA, Custer LJ, Cerna CM, and Narala K (1994). Quantification of phytoestrogens in legumes by HPLC. J Agric Food Chem 42:1905-1913. 
Gerhard M, Walsh BW, Tawakol A, Haley EA, Crager SJ, Seely EW, Ganz P, and Creager MA (1998). Estradiol therapy combined with progesterone and endothelium-dependent vasodilation in postmenopausal women. Circulation 12: 1158-1163.

Goetz RM, Thatte HS, Prabhakar P, Cho MR, Michel T, and Golan DE (1999). Estradiol induces the calcium-dependent translocation of endothelial nitric oxide synthase. Proc Natl Acad Sci USA 96:2788-2793.

Grady D, Gebretsadik T, Kerlikowske, K, Ernster V, and Pettiti D (1995). Hormone replacement therapy and endometrial cancer risk: A meta-analysis. Obstet Gynecol 85:304-313.

Grady D, Rubin SM, Pettiti DB, Fox CS, Black D, Ettinger B, Ernster VL, and Cummings SR (1992). Hormone therapy to prevent diseases and prolong life in postmenopausal women. Ann Intern Med 117:549-556.

Hayashi T, Fukuto JM, Ignarro LJ, and Chaushuri G (1992). Basal release of nitric oxide from aortic rings is greater in female rabbits than in male rabbits: Implications for atherosclerosis. Proc Natl Acad Sci USA 89:11259-11263.

Hulley S, Grady D, Bush T, Furberg C, Herrington D, Riggs B, and Vittinghoffl E (1998). Randomized trial of estrogen plus progestin for secondary prevention of coronary heart disease in postmenopausal women. Heart and Estrogen/Progestin Replacement Study (HERS) Research Group. JAMA 280: 605-613.

Jimenez M and Mateo R (1997). Determination of mycotoxins produced by Fusarium isolates from banana fruits by capillary gas chromatography and high-performance liquid chromatography. J Chromatogr A 778:363-372.

Kleinert H, Wallerath T, Euchenhofer C, Ihrig-Biedert I, Li H, and Forstermann $U$ (1998). Estrogens increase transcription of the human endothelial NO synthase gene: Analysis of the transcription factors involved. Hypertension 31:582-584.

Knight DC and Eden JA (1995). Phytoestrogens: A short review. Maturitas 22:167-175.

Knight DC and Eden JA (1996). A review of the clinical effects of phytoestrogens. Obstet Gynecol 87:897-904.

Lip GY, Blann AD, Jones AF, and Beevers DG (1997). Effects of hormone-replacement therapy on hemostatic factors, lipid factors, and endothelial function in women undergoing surgical menopause: Implications for prevention of atherosclerosis. Am Heart J 134:764-771.

Losordo DW, Kearney M, Kim EA, Jekanowski J, and Isner JM (1994). Variable expression of the estrogen receptor in normal and atherosclerotic coronary arteries of postmenopausal women. Circulation 89:1501-1510.
Makela SI, Pylkkanen LH, Santti RS, and Adlercreuts H (1995). Dietary soybean may be anti-estrogenic in male mice. J Nutr 125:437-445.

Miksicek RJ (1994). Interaction of naturally occurring nonsteroidal estrogens with expressed recombinant human estrogen receptor. J Steroid Biochem Mol Biol 49:153-160.

Oparil S and Arthur C (1999). Corcoran Memorial Lecture. Hormones and vasoprotection. Hypertension 33:170-176.

Prelusky DB, Werner RM, and Trenholm HL (1989). Sensitive analysis of the mycotoxin zearalenone and its metabolites in biological fluids by high-performance liquid chromatography alpha. J Chromatogr 494:267-277.

Robinson RW, Higano N, and Cohen WD (1963). Long-term effects of high dosage estrogen therapy in men with coronary heart disease. J Chron Dis 16:155-161.

Seeger H, Mueck AO, and Lippert TH (1999). Effect ofestradiol metabolites on prostaglandin synthesis in human endothelial cell cultures. Life Sci 65:167-170.

Squadrito F, Altavilla D, Squadrito G, Campo GM, loculano M, Canale P, Rossi F, Saitta A, and Caputi AP (1996). Effects of S-ethylisothiourea, a potent inhibitor of nitric oxide synthase, alone or in combination with a nitric oxide donor in splanchnic artery occlusion shock. Br J Pharmacol 119:2328.

Squadrito F, Altavilla D, Squadrito G, Campo GM, Arlotta M, Arcoraci V, Minutoli L, Serrano M, Saitta A, and Caputi AP (1997). $17 \beta$-oestradiol reduces cardiac leukocyte accumulation in myocardial ischaemia reperfusion injury in rats. Eur J Pharmacol 335:185-192.

Stahl S, Chun T, and Gray WG (1998). Phytoestrogens act as estrogen agonists in a estrogen-responsive pituitary cell line. Toxicol Appl Pharmacol 152:41-48.

Van Baal WM, Kenemans P, Emeis JJ, Schalkwijk CG, Mijatovic V, Van Der Mooren MJ, Vischer UM, and Stehouwer CD (1999). Long-term effects of combined hormone replacement therapy on markers of endothelial function and inflammatory activity in healthy postmenopausal women. Fertil Steril 71:663-670.

Walsh BA, Mullick AE, Walzen RL, and Rutledge JC (1999). $17 \beta$-estradiol reduces tumor necrosis factor- $\alpha$ mediated LDL accumulation in the artery wall. J Lipid Res 40:387-396.

Wang $\mathrm{H}$ and Murphy $\mathrm{P}$ (1994). Isoflavone content in commercial soybean foods. J Agric Food Chem 46:1666-1673.

Whitten PL and Naftolin F (1992). Effects of a phytoestrogen diet on estrogen-dependent reproductive processes in immature female rats. Steroids 57:443-449. 